\title{
Article \\ An Opportunity to Understand Concerns about COVID-19 Vaccination: Perspectives from EMS Professionals
}

\author{
Sarah R. MacEwan ${ }^{1,2, *}$, Alice A. Gaughan ${ }^{2}$, Megan E. Gregory ${ }^{2,3} \oplus$, Laura J. Rush ${ }^{2} \oplus$, Jonathan R. Powell ${ }^{4,5}{ }^{\oplus}$, \\ Jordan D. Kurth ${ }^{4}\left(\mathbb{D}\right.$, Ashish R. Panchal ${ }^{4,5,6}$ and Ann Scheck McAlearney ${ }^{2,3,7}$ (]) \\ 1 Division of General Internal Medicine, College of Medicine, The Ohio State University, Columbus, OH 43210, USA \\ 2 The Center for the Advancement of Team Science, Analytics, and Systems Thinking (CATALYST), \\ College of Medicine, The Ohio State University, Columbus, OH 43210, USA; \\ Alice.Gaughan@osumc.edu (A.A.G.); Megan.Gregory@osumc.edu (M.E.G.); Laura.Rush@osumc.edu (L.J.R.); \\ Ann.McAlearney@osumc.edu (A.S.M.) \\ 3 Department of Biomedical Informatics, College of Medicine, The Ohio State University, Columbus, OH 43210, USA \\ 4 National Registry of Emergency Medical Technicians, Columbus, OH 43229, USA; jpowell@nremt.org (J.R.P.); \\ jkurth@nremt.org (J.D.K.); Ashish.Panchal@osumc.edu (A.R.P.) \\ 5 Division of Epidemiology, College of Public Health, The Ohio State University, Columbus, OH 43210, USA \\ 6 Department of Emergency Medicine, The Ohio State University Wexner Medical Center, \\ Columbus, OH 43210, USA \\ 7 Department of Family and Community Medicine, College of Medicine, The Ohio State University, \\ Columbus, $\mathrm{OH} 43210$, USA \\ * Correspondence: Sarah.MacEwan@osumc.edu
}

Citation: MacEwan, S.R.; Gaughan,

A.A.; Gregory, M.E.; Rush, L.J.;

Powell, J.R.; Kurth, J.D.; Panchal,

A.R.; McAlearney, A.S. An

Opportunity to Understand Concerns about COVID-19 Vaccination:

Perspectives from EMS Professionals.

Vaccines 2022, 10, 380. https://

$10.3390 /$ vaccines 10030380

Academic Editors: Annalisa Rosso,

Azzurra Massimi, Gianluca Voglino

and Maria Rosaria Gualano

Received: 4 February 2022

Accepted: 27 February 2022

Published: 2 March 2022

Publisher's Note: MDPI stays neutral with regard to jurisdictional claims in published maps and institutional affiliations.

Copyright: (C) 2022 by the authors. Licensee MDPI, Basel, Switzerland. This article is an open access article distributed under the terms and conditions of the Creative Commons Attribution (CC BY) license (https:// creativecommons.org/licenses/by/ $4.0 /)$.

\begin{abstract}
Some healthcare professionals, including emergency medical service (EMS) professionals, remain hesitant about receiving COVID-19 vaccines. This study sought to understand EMS professionals' perspectives regarding COVID-19 vaccination. Using open-ended comments from a national survey deployed electronically to over 19,000 EMS professionals in April of 2021, we examined perspectives about acceptance of and hesitancy toward COVID-19 vaccines. Survey comments revealed differences in perspectives between vaccinated and unvaccinated EMS professionals regarding their personal role in improving public health through COVID-19 vaccination as well as vaccine benefits and the protection conferred by vaccination. Unvaccinated individuals also expressed concerns over the research and development of the COVID-19 vaccines that led to their decision not to get vaccinated. Individuals who were vaccinated suggested ways to increase uptake of the vaccine including having healthcare professionals serve as leaders for vaccination and educating individuals about COVID-19 vaccination through credible resources. Vaccine hesitancy remains a challenge to achieving herd immunity to COVID-19 through vaccination, even among healthcare professionals. Understanding the perspectives of those who have chosen not to be vaccinated can help direct strategies to reduce confusion and concerns. The perspectives of vaccinated individuals may also be valuable in identifying opportunities to promote vaccination in the professional setting.
\end{abstract}

Keywords: COVID-19; vaccination; vaccine hesitancy; emergency medical service

\section{Introduction}

Vaccination is a critical tool in the fight against COVID-19. The vaccines available in the U.S. prevent infection and lessen severe illness [1-3], as well as reduce transmission [4]. Despite these benefits, vaccine hesitancy leading to the refusal of COVID-19 vaccines has become a significant barrier to achieving herd immunity through vaccination [5]. Of those 18 years or older in the U.S., only 73.4\% had been fully vaccinated as of January, 2022 [6].

Despite their increased exposure to COVID-19 and risk of infection, vaccine hesitancy is present in healthcare workers, with some having delayed or refused to receive a COVID19 vaccine [7]. Due to their high risk of exposure, the CDC recommends prioritization of healthcare workers for COVID-19 vaccination [8], and mandates have been introduced 
as an approach to bolster vaccination in this workforce [9]. Many states and employers, however, have not implemented COVID-19 vaccine mandates due to high levels of vaccine hesitancy. Improving our understanding of vaccine hesitancy can help inform efforts to increase voluntary vaccination as this is critical during the ongoing pandemic.

Emergency medical service (EMS) professionals, such as paramedics and emergency medical technicians (EMTs), are a critical part of the healthcare infrastructure, often serving as a first point of contact for patients [10]. Vaccination of EMS professionals is important for their health, the health of their patients, and the strength of the EMS workforce. Despite the significant role of EMS professionals and the benefits of their vaccination against COVID-19, only $70 \%$ were vaccinated according to a survey conducted in April 2021 [11]. Unfortunately, studies investigating EMS perspectives about COVID-19 vaccines and their hesitancy are lacking. As part of a larger project involving a national survey of EMS professionals and their experience with COVID-19 during the pandemic, we investigated the openended comments provided in survey responses to better understand EMS professionals' perspectives about COVID-19 vaccines.

\section{Materials and Methods}

This is a subset analysis of a larger study on vaccine hesitancy for which summary results have been previously published [11]. In this electronic survey of EMS professionals, vaccination status was determined by the response to the question, "Have you received a COVID-19 vaccine?" The survey asked participants why they did or did not receive the vaccine, as well as evaluate factors related to vaccine acceptance and hesitancy including perceived risk of COVID-19, confidence in the COVID-19 vaccine, and medical mistrust, using validated or adapted scales [12-14]. Demographic characteristics were acquired from the National EMS Certification database. Results from the analysis of quantitative variables are described elsewhere [11]. The survey also allowed participants the option to provide comments explaining their vaccination decision as well as anything else they wished to share about COVID-19 vaccines. Qualitative analysis of these open-ended comments is the focus of this subset analysis.

The survey was distributed to a simple random sample of 19,062 EMS professionals in the National Registry of Emergency Medical Technicians' (National Registry) database. The National Registry is the national certification agency for EMS professionals in the U.S. The database contains contact information for approximately 420,000 EMS professionals [15]. A link to the survey was emailed, with follow-up emails sent one and two weeks later [16]. The survey was distributed in April 2021, after vaccinations were widely available to these professionals in the U.S., but before full FDA approval of any COVID-19 vaccines and before COVID-19 vaccine mandates were commonplace. To evaluate non-response bias, a non-response survey was sent out to eligible participants that received an invitation to the original survey but did not submit a response. This non-response survey only asked for the participant's vaccination status. There was not an opportunity to provide open-ended comments in the non-response survey.

Participants who did not provide open-ended comments were dropped from analysis. Descriptive statistics were computed for demographics and vaccination status. Differences in demographics between unvaccinated and vaccinated respondents were evaluated by Chi-square tests for categorical variables and independent samples $t$-test for continuous variables. Open-ended comments were coded for content using thematic analysis [17], supported by the use of the ATLAS.ti software program. All quotations are presented verbatim. This study was approved by the authors' Institutional Review Board.

\section{Results}

A total of 2581 participants responded to the survey (response rate $=14 \%$ ). Of these, $1145(44.4 \%)$ provided at least one open-ended comment; $727(63.5 \%)$ of those who provided comments were vaccinated, and $417(36.4 \%)$ were unvaccinated. One participant's 
vaccination status was unknown. Demographics of participants who provided at least one open-ended comment are presented in Table 1.

Table 1. Demographics of participants who provided at least one open-ended comment.

\begin{tabular}{|c|c|c|c|c|}
\hline Characteristic & Overall & $\begin{array}{c}\text { Unvaccinated } \\
(\mathrm{N}=417,36.4 \%)\end{array}$ & $\begin{array}{c}\text { Vaccinated } \\
(\mathrm{N}=727,63.5 \%)\end{array}$ & $p$ (Unvaccinated vs. \\
\hline Sex-n $(\%)$ & & & & 0.59 \\
\hline Female & $377(32.9)$ & $141(33.8)$ & $236(32.5)$ & \\
\hline Male & $753(65.8)$ & $269(64.5)$ & $483(66.4)$ & \\
\hline Missing & $15(1.3)$ & $7(1.7)$ & $8(1.1)$ & \\
\hline Age $-n(\%)$ & & & & $<0.001$ \\
\hline$<28$ years & $232(20.3)$ & $113(27.1)$ & $119(16.4)$ & \\
\hline $29-38$ years & $292(25.5)$ & $129(30.9)$ & $163(22.4)$ & \\
\hline $39-50$ years & $296(25.9)$ & $93(22.3)$ & $202(27.8)$ & \\
\hline$>51$ years & $325(28.4)$ & $82(19.7)$ & $243(33.4)$ & \\
\hline Race and Ethnicity- $n(\%)$ & & & & 0.45 \\
\hline White, Non-Hispanic & $967(84.5)$ & $357(85.6)$ & $609(83.8)$ & \\
\hline All others & $134(11.7)$ & $45(10.8)$ & $89(12.2)$ & \\
\hline Missing & $44(3.8)$ & $15(3.6)$ & $29(4.0)$ & \\
\hline Certification- $n(\%)$ & & & & 0.01 \\
\hline Basic Life Support & $418(36.5)$ & $172(41.2)$ & $246(33.8)$ & \\
\hline Advanced Life Support & $727(63.5)$ & $245(58.8)$ & $481(66.2)$ & \\
\hline Educational Level- $n(\%)$ & & & & $<0.001$ \\
\hline HS/GED & $113(9.9)$ & $44(10.6)$ & $69(9.5)$ & \\
\hline Some College & $327(28.6)$ & $146(35.0)$ & $181(24.9)$ & \\
\hline Associate's & $220(19.2)$ & $78(18.7)$ & $141(19.4)$ & \\
\hline Bachelor's & $250(21.8)$ & $69(16.5)$ & $181(24.9)$ & \\
\hline Master's/Doctorate & $79(6.9)$ & $18(4.3)$ & $61(8.4)$ & \\
\hline Missing & $156(13.6)$ & $62(14.9)$ & $94(12.9)$ & \\
\hline Urbanicity- $n(\%)$ & & & & 0.02 \\
\hline Rural & $390(34.1)$ & $167(40.0)$ & $222(30.5)$ & \\
\hline Suburban & $465(40.6)$ & $152(36.5)$ & $313(43.1)$ & \\
\hline Urban & $202(17.6)$ & $57(13.7)$ & $145(19.9)$ & \\
\hline Missing & $88(7.7)$ & $41(9.8)$ & $47(6.5)$ & \\
\hline $\begin{array}{l}\text { Has a health condition that makes them at } \\
\text { high risk for increased COVID-19 disease } \\
\text { severity- } n(\%)\end{array}$ & & & & $<0.001$ \\
\hline No & $714(62.4)$ & $280(67.1)$ & $433(59.6)$ & \\
\hline Yes & $346(30.2)$ & $99(23.7)$ & $247(34.0)$ & \\
\hline Missing & $85(7.4)$ & $38(9.1)$ & $47(6.5)$ & \\
\hline Agency Type- $n(\%)$ & & & & 0.40 \\
\hline Fire & $283(24.7)$ & $109(26.1)$ & $174(23.9)$ & \\
\hline Private & $254(22.2)$ & $91(21.8)$ & $163(22.4)$ & \\
\hline Government Non-fire & $149(13.0)$ & $53(12.7)$ & $95(13.1)$ & \\
\hline Hospital & $124(10.8)$ & $35(8.4)$ & $89(12.2)$ & \\
\hline Other * & $116(10.1)$ & $42(10.1)$ & $74(10.2)$ & \\
\hline Missing & $219(19.1)$ & $87(20.9)$ & $132(18.2)$ & \\
\hline Service Type- $n(\%)$ & & & & 0.64 \\
\hline 911 & $350(30.6)$ & $127(30.5)$ & $223(30.7)$ & \\
\hline All Others ** & $141(12.3)$ & $48(11.5)$ & $93(12.8)$ & \\
\hline Missing & $654(57.1)$ & $242(58.0)$ & $411(56.5)$ & \\
\hline
\end{tabular}


Table 1. Cont.

\begin{tabular}{ccccc}
\hline Characteristic & Overall & $\begin{array}{c}\text { Unvaccinated } \\
\mathbf{( N = 4 1 7 , 3 6 . 4 \% )}\end{array}$ & $\begin{array}{c}\text { Vaccinated } \\
\mathbf{( N = 7 2 7 , 6 3 . 5 \% )}\end{array}$ & $\begin{array}{c}p \text { (Unvaccinated vs. } \\
\text { Vaccinated) }\end{array}$ \\
\hline Years in EMS-mean (IQR) & $15.1(18.0)$ & $12.7(16.0)$ & $16.5(19.0)$ & $<0.001$ \\
\hline Employment Status-n $(\%)$ & & & & 0.22 \\
Full-Time & $666(58.2)$ & $247(59.2)$ & $418(57.5)$ \\
Part-Time & $123(10.7)$ & $38(9.1)$ & $85(11.7)$ \\
Volunteer & $108(9.4)$ & $33(7.9)$ & $75(10.3)$ \\
Missing & $248(21.7)$ & $99(23.7)$ & $149(20.5)$ \\
\hline
\end{tabular}

Abbreviations: HS/GED, High school/General Educational Development; IQR, Interquartile range; MIHCP Mobile Integrated Healthcare or Community Paramedicine. * Other includes air medical, tribal, military, and other; ** All Others includes medical transport, 911 and medical transport, clinical services, MIHCP, and other. $p$-values are based on Chi-square tests for categorical variables and independent samples $t$-test for continuous variables.

Open-ended responses revealed three main topics that were of particular interest regarding participants' perspectives about COVID-19 vaccination: (1) personal responsibility for COVID-19 vaccination, (2) vaccine development, and (3) opportunities to promote vaccination. Each of these topics is discussed further below, with a summary of our findings presented in Figure 1.

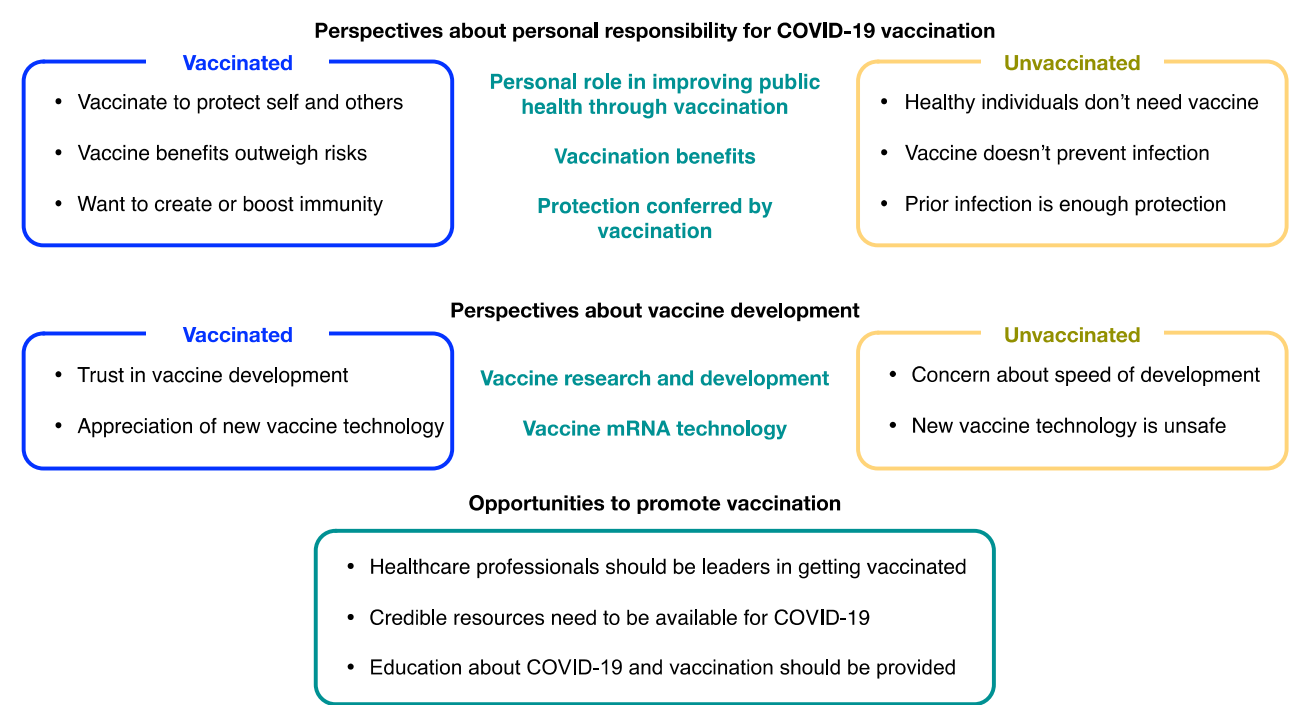

Figure 1. Perspectives of EMS Professionals about COVID-19 vaccination.

\subsection{Perspectives about Personal Responsibility for COVID-19 Vaccination}

We found markedly divergent perspectives about personal responsibility for COVID19 vaccination among vaccinated and unvaccinated participants in three areas: (1) individual role in improving public health through vaccination, (2) benefits of vaccination, and (3) protection conferred from vaccination. Contrasting perspectives of vaccinated and unvaccinated participants are presented below, with additional representative quotations provided in Table 2.

Participants were divided in their perspectives about their individual role in improving public health through vaccination. Many vaccinated respondents explained that the reason they received a COVID-19 vaccine was to protect themselves and others, whereas unvaccinated respondents rarely mentioned protecting others. One vaccinated respondent shared, "I think that everyone should get vaccinated so we can protect each other and our communities". Unvaccinated individuals commonly commented that they did not feel there was a need for vaccination for an illness they perceived to be mild and which presented a low risk for themselves. For example, one unvaccinated respondent explained: “With such a low mortality rate and often minor illness from infection, I don't see the need 
for a fit, healthy, younger person to get an experimental vaccine that is NOT certain to protect me from a disease that is still not that bad in general".

Table 2. Perspectives about personal responsibility for COVID-19 vaccination.

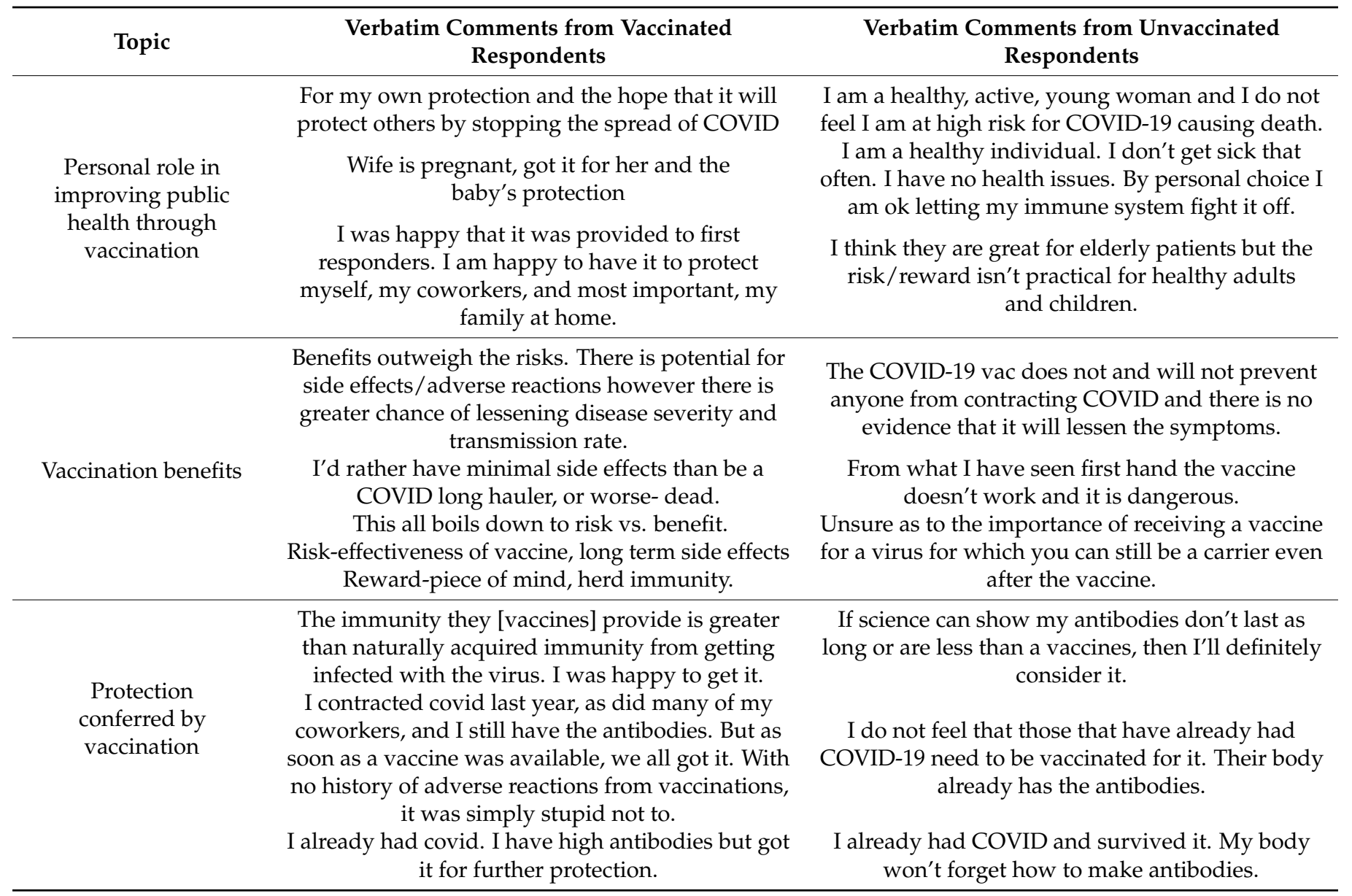

Participants were also divided in their perspectives about COVID-19 vaccination benefits. Responses ranged from feelings that the vaccines' benefits outweigh the risks of COVID-19 infection, to feelings that the vaccines do not work and thus have no benefit at all. For example, a vaccinated respondent explained, "The risks of COVID and side effects are far greater than the effects of receiving the vaccine. I have been vaccinated. I had some side effects, but the side effects of COVID are far worse than the vaccination". Some unvaccinated individuals did not appreciate the role of the vaccine in reducing severe illness and doubted the benefit of a vaccine that did not completely prevent infection. One unvaccinated respondent shared, "It is not a vaccine. It is a shot that minimizes the effects of the disease. This so-called vaccine doesn't prevent anything".

Perspectives regarding the protection conferred by COVID-19 vaccination also differed between vaccinated and unvaccinated participants. A vaccinated respondent shared, "I chose to get a vaccine even though I had already had COVID-19. My understanding is that the immunity from the vaccination is likely to be longer lasting than that from infection". In contrast, many unvaccinated individuals did not recognize additional protection provided by a COVID-19 vaccine if they had been previously infected. As one unvaccinated respondent noted, "If I have antibodies from getting over COVID-19, like any other, I have antibodies. I don't need the vaccine". 


\subsection{Perspectives about Vaccine Development}

Perspectives about vaccine development were also divided. Although vaccinated participants reported trust in vaccine development, unvaccinated participants expressed concern specifically in two areas: (1) vaccine research and development, and (2) mRNA vaccine technology. Perspectives of vaccinated and unvaccinated participants about these areas are presented below, with representative quotations listed in Table 3.

Table 3. Perspectives about vaccine development.

\begin{tabular}{ccc}
\hline Topic & $\begin{array}{c}\text { Verbatim Comments from Vaccinated } \\
\text { Respondents }\end{array}$ & $\begin{array}{c}\text { Verbatim Comments from Unvaccinated } \\
\text { Respondents }\end{array}$ \\
\hline
\end{tabular}

Due to the amount of funding the pharmaceutical companies received, I believe the speed of research and development was as good as the routine $R \& D$ used by the companies under normal conditions. As a paramedic and microbiologist, I know that 30 years of research has gone into this vaccine.

Without commercial investment interests governing the COVID-19 vaccine development, this went smoothly. We should do this for all vaccines moving forward.

I feel better knowing the basic underlying science/research began far before COVID-19.

I am excited for the future of mRNA vaccines and medications.

While the vaccine was developed quickly, the mRNA vaccine has been around for a while. The vaccine is just as safe as any other vaccine that was developed over a longer period of time.

Vaccine mRNA technology
I'm not willing to be a guinea pig if I don't have to be. It was produced too quickly for my trusting.

There simply hasn't been enough research or data to support it's safety and effectiveness.

I personally prefer to wait until I feel my family and I have more scientific research regarding the safety of these vaccines.

MRNA is not safe, it can get into the brain barrier causing damage and possible death. There is other resources and research out there available now and people should pay attention. We're in danger.

MRNA inoculations/modifiers have been attempted in the past and have failed long term.

I have specific questions about mRNA vaccines and have asked experts and gotten no answers. dead/alive. Knowing that mRNA has a very short
half-life and will not stay in your system for long is also huge in letting people know that it has a much smaller risk of causing any long-term effects when compared to other vaccinations.

People need to know that mRNA development is much different than using any part of the virus

Vaccinated respondents stressed that they were confident in the development of the vaccine, citing that research prior to the pandemic was valuable for vaccine development and that extraordinary research support during the pandemic allowed the vaccines to be developed quickly. One vaccinated respondent explained, "I think there are a lot of misconceptions and everyone is worried about how fast it got developed without taking into account all other research virtually stopped and that was the only thing being researched by everyone with all the funding needed". For many unvaccinated participants, however, the vaccine research and development was a source of concern. The speed of development was one concern, as an unvaccinated respondent noted, "I do not think that this vaccine is safe due to how fast it was made and put out". Unvaccinated participants also were concerned about a lack of information regarding evidence from the research and development process. Another unvaccinated respondent noted, "Ultimately, the reason I am not getting vaccinated is because I want to see the evidence-based research behind it all. I don't want the first batch of it. As we saw with the Johnson and Johnson one, there are adverse effects".

New vaccine technology was also a topic that both vaccinated and unvaccinated participants commented on, with vaccinated and unvaccinated respondents having split 
perspectives on mRNA vaccines. A vaccinated respondent shared, "I wish people understood that this type of vaccine, using mRNA, has been in development for much longer than the pandemic has been around". A respondent who was unvaccinated explained they did not get the vaccine because "there is no long-term study to look at effects of mRNA vaccines on the body".

\subsection{Opportunities to Promote Vaccination}

Vaccinated participants suggested three specific opportunities related to changing others' perspectives about COVID-19 vaccination: (1) healthcare professionals to serve as leaders for vaccination; (2) improve the availability of credible COVID-19 vaccine-related resources; and (3) focus on efforts to educate healthcare professionals and the public on COVID-19 vaccination facts. These opportunities are discussed next, with additional representative quotations presented in Table 4.

Table 4. Opportunities to promote vaccination.

\begin{tabular}{c}
\hline Topic \\
\hline $\begin{array}{c}\text { Healthcare professionals should be } \\
\text { leaders in getting vaccinated }\end{array}$
\end{tabular}

leaders in getting vaccinated

\section{Verbatim Comments from Vaccinated Respondents}

I feel extremely confident on the safety and protection of the vaccine. Health care professionals should be a leader on getting the vaccine.

EMS should be setting the example. I would argue if a provider doesn't support the science behind the vaccine, then perhaps they are in the wrong profession. Lead by example.

There is a lot of misinformation and disinformation out there about the vaccine and COVID-19.

Credible resources need to be available for COVID-19
There's too much misinformation concerning the vaccines that has been made widely available and propagated.

I think that getting the right information out is important.

I was stunned by the number of people in EMS and nursing who do not understand how vaccination technologies work and spread misinformation

Education about COVID-19 and vaccination should be provided
I feel that a large portion of the general public is extremely uneducated about the vaccine.

The social stigma around vaccines shows the public has a very low amount of knowledge about science and how a mRNA vaccine works.

First, comments made by vaccinated respondents highlighted that many EMS professionals felt that healthcare professionals should be leaders in obtaining vaccinations. One respondent noted, "It is our duty as EMTs to be an example to our community and show them that this is the best course of action as we know it". Similarly, another explained the reason they received the vaccine was "to set a positive example for the community and, set the example for fellow employees".

The need for credible resources to dispel misinformation was also highlighted as an opportunity. One respondent shared, "There is too much misinformation floating around the medical community about the SARS-CoV-2 vaccine and until this changes, it is likely that the public will remain even more misinformed". Similarly, another noted, "There is a copious amount of misinformation about the various vaccines that even other health professionals sometimes fall victim to".

Third, many emphasized the importance of educating healthcare professionals and the public about COVID-19 vaccines. Vaccinated individuals were frustrated with the lack of understanding of vaccines that they saw. With regard to the public, one respondent commented, "There needs to be a more concerted effort to educate the public on the facts and not the myths [about COVID-19 vaccines]". Another stressed the need to educate professionals, such as EMS, who can then help educate the public with whom they interact: "If this vaccine is to be understood better, I think those in contact with the public need better information and education to learn and to be able to help the public become more educated. You are missing your best resource". 


\section{Discussion}

Our study revealed differing views between vaccinated and unvaccinated EMS professionals regarding the necessity and benefits of COVID-19 vaccines. These contrasting perspectives also shed light on the concerns that may contribute to vaccine hesitancy, including distrust in rapid vaccine development and uncertainty about the safety of new vaccine technology. Although our study focused on the perspectives of EMS professionals, these sentiments are reflected in other populations including other healthcare professionals $[7,18]$ and the general public [19]. When viewed through the lens of the World Health Organization's 3-C model of vaccine hesitancy, which considers factors of vaccine hesitancy related to confidence, complacency, and convenience [20], it was interesting to note that study participants did not express concerns related to vaccine convenience, such as vaccine availability or accessibility. This may be related to the prioritization of vaccine access for this population due to their occupational risk. Study participants did, however, express concerns related both to vaccine confidence (e.g., trust in vaccine effectiveness and safety) and complacency (e.g., lack of perceived risk of COVID-19 or benefit of vaccination), suggesting strategies to address vaccine hesitancy in populations such as first responders should focus on these factors as they impact vaccination decision making.

Participants also noted opportunities to increase vaccine acceptance, including the opportunity to lead by example, the opportunity to present credible sources of information, and the opportunity to improve education around COVID-19 and vaccination. EMS professionals and first responders were among the first groups to receive access to COVID-19 vaccines, and many were eager to be vaccinated, to both protect themselves and show their support of vaccination efforts [21,22]. Supporting this enthusiasm, we found vaccinated respondents who highlighted their opportunity to lead by example, both for their coworkers and for the public. In practice, when interacting with the public, EMS professionals can be a valuable source of information about vaccination and can relay their confidence in the vaccines. These messages can be powerful, as EMS professionals are often viewed as trusted providers in their communities [23]. Among coworkers, leading by example creates the opportunity to dispel misinformation about vaccination, while building camaraderie through commonalities in goals to conserve life, alleviate suffering, promote health, and do no harm [24]. Leadership support, open communication, and opportunities to ask questions can also help increase confidence among those individuals who have concerns that fuel their vaccine hesitancy $[25,26]$.

Our vaccinated participants also appeared to recognize the need for credible sources of information regarding COVID-19 and COVID-19 vaccines. This need was supported by the corresponding mistrust that unvaccinated participants relayed in their comments. Many unvaccinated participants indicated that they did not trust the vaccine, reporting feeling that it was unsafe, rushed, and ineffective or not needed. These opinions were often counter to scientific evidence and in opposition to official messaging from healthcare and government sources (e.g., "The side effects of the vaccine far exceed the severity of COVID in $99 \%$ of patients", which is directly counter to evidence showing that side effects of COVID-19 far outweigh those of the vaccine) [27].

According to a survey by the Kaiser Family Foundation, 54\% of adults believe or are unsure about the validity of misinformation about the COVID-19 vaccines, including whether the vaccines can cause COVID-19, cause infertility, change DNA, contain fetal cells, or are not needed if one has already had COVID-19 [28]. These concerns were all noted by participants in our study, indicating that the pervasiveness of misinformation extends to EMS professionals. However, all of these statements are counter to scientific evidence [29]. Our prior work found that EMS professionals-particularly those who were unvaccinated against COVID-19-had low trust in the official information sources that typically communicate about this evidence, including government and healthcare sources [11]. More research is needed to understand who vaccine-hesitant individuals do trust. It is possible that trust may need to be considered on an individual level. That is, each person may look to someone they feel is in their "ingroup" for trusted information-a 
community member they relate to, a favored national icon, or someone who a person can simply see themselves in (e.g., similar age, race, health conditions, etc.) [30]. For the EMS population, perhaps a respected figure in the EMS profession would make an ideal vaccine role model. When considering what should be communicated by trusted individuals, the National Academies of Sciences, Engineering, and Medicine recommend that information provided be new, personally relevant, and salient in order to influence change [31].

Another challenge to be considered is addressing what happens when trust is broken. Trust violations can be considered either competence-based (i.e., unintentional, due to deficit in knowledge, mistakes) or intent-based (i.e., intentional, to advance one's own motives at the expense of another) [32]. The former tends to be more easily repaired, whereas the latter can result in long-lasting loss of trust [32]. A common source of low trust in COVID-19 vaccines is changing information that has been commonplace throughout the pandemic $[33,34]$. While this was largely due to the science of COVID-19 playing out in real-time, scientifically naive individuals may have interpreted this more deviously (i.e., as an intent-based trust violation due to an ulterior motive). For example, when Dr. Anthony Fauci's emails were released in summer 2021, showing he had told a contact in February 2020 that masking was not protective to the wearer [35], some prescribed this as a competence-based violation wherein the benefits of masking to prevent COVID-19 were not known at that early stage [36]; others positioned this as evidence of an intentional, malicious violation, such that Dr. Fauci and others were later engaged in providing purposeful false information regarding facemasks [37]. This indicates a need for messaging that recognizes information changes are related to evolving science and are to be expected. It is also important to be clear about the level of confidence in current scientific findings (e.g., we expect the vaccines will be-or can be made-effective for preventing severe disease for future variants, but it is possible a variant can develop that escapes vaccine immunity) [38], as well as about what findings are extremely unlikely to change (e.g., the COVID-19 vaccines cannot and will not change one's DNA) [39]. This clarity may help individuals interpret changing information as a competence-based violation, which is more easily repairable in comparison to a more malicious intent-based trust violation.

Finally, vaccinated respondents recognized the need for improved education to promote vaccine acceptance. The prevalence of negative perspectives about vaccination, suggesting a need for improved understanding of vaccines, is concerning, especially among medical professionals. However, this may be less surprising among EMS professionals whose education standards do not include topics relevant to research methods, to interpretation of current vaccine literature, or to the immunological understanding of vaccines [40]. These topics are not core learning objectives in the delivery of acute lifesaving prehospital care, though they are important in other healthcare professions (e.g., physicians, nurses). Additionally, the depth of knowledge in these areas also may not be possible in the short time frames of EMS education. These educational limitations may have contributed to the susceptibility of EMS professionals to misinformation. Our findings suggest potential benefits to introducing topics relevant to vaccination, particularly related to patient and provider safety, into EMS curriculum, continuing education, or license renewal opportunities.

Sources of vaccine hesitancy found in our study are reflected in the perspectives of healthcare professionals and students in other countries [41], including similarly divided perspectives related to personal responsibility, effectiveness, and safety of booster vaccination [42]. However, it is important to note that vaccination acceptance rates in the U.S. have lagged behind other countries [43], where some countries have achieved over $90 \%$ initial vaccination as of February 2022 [44]. Notably, the U.S. also lags in booster vaccinations, achieving only 28 COVID-19 boosters per 100 people as of February 2022, in comparison to other countries where boosters have been received by greater than $50 \%$ of the population [44]. These statistics highlight the importance of addressing vaccine hesitancy in the U.S., where factors related to vaccine acceptance likely go beyond resources and access, including factors such as the politicization of vaccination that has led to pockets of unvaccinated populations [45]. 
Our study is limited in that it relied on the open-ended comments acquired from a larger survey that explored EMS professionals' perspectives about COVID-19 vaccination. Response to these open-ended questions was optional, and not all survey participants provided comments. A study that focuses solely on eliciting EMS professional perspectives about the topics revealed in our analysis may provide additional depth to our understanding of the beliefs, concerns, and suggestions we found. Furthermore, our survey did have a relatively low response rate (14\%); however, this response rate was typical of this study population and recruitment mechanism [46-50]. We did conduct a non-response survey as a part of our larger study, which demonstrated no difference in vaccination acceptance with our initial survey, supporting our belief that our low response rate did not result in biased responses [11].

\section{Conclusions}

EMS professionals have the opportunity to exemplify actions for the greater good by helping to protect the frontline workforce (e.g., first responder colleagues and hospital staff), patients, and their families and community members by being vaccinated. This study revealed beliefs and concerns about COVID-19 vaccination that may contribute to vaccine hesitancy among EMS professionals; although, these perspectives have been similarly noted in the general population. There is a heightened need to understand vaccine hesitancy and take appropriate actions to dispel it in light of the evolving information about booster shots, variants, and the reality that COVID-19 will be with us for some time. It is important to act now to reduce vaccine hesitancy among EMS professionals and the population at large.

Author Contributions: Conceptualization, S.R.M., M.E.G., L.J.R., J.R.P., J.D.K., A.R.P. and A.S.M.; methodology, S.R.M., M.E.G., L.J.R., J.R.P., J.D.K., A.R.P. and A.S.M.; validation, S.R.M., A.A.G., M.E.G., L.J.R. and A.S.M.; formal analysis, S.R.M., A.A.G., M.E.G., L.J.R. and A.S.M.; investigation, M.E.G., J.R.P., J.D.K., A.R.P. and A.S.M.; resources, A.R.P. and A.S.M.; data curation, M.E.G., J.R.P., J.D.K. and A.R.P.; writing-original draft preparation, S.R.M., A.A.G., M.E.G., L.J.R., J.R.P., J.D.K., A.R.P. and A.S.M.; writing-review and editing, S.R.M., A.A.G., M.E.G., L.J.R., J.R.P., J.D.K., A.R.P. and A.S.M.; visualization, S.R.M., A.A.G. and M.E.G.; supervision, A.R.P. and A.S.M.; project administration, A.R.P. and A.S.M.; funding acquisition, A.R.P. and A.S.M. All authors have read and agreed to the published version of the manuscript.

Funding: This study was supported by a grant [\#U54CA260582] from the National Cancer Institute (NCI), but the NCI was not involved in the data collection, analysis, nor the decision to present these findings.

Institutional Review Board Statement: This study was approved by the American Institutes for Research's Institutional Review Board (\#EX00546) on 26 March 2021.

Informed Consent Statement: Informed consent was obtained from all subjects involved in the study. Participants were provided consent information at the beginning of the survey instrument, which explained that by clicking "next" to complete the survey they were providing their informed consent to participate.

Data Availability Statement: Due to participant privacy concerns, the data presented in this study are not publicly available. The data may be requested from the corresponding author.

Conflicts of Interest: The authors declare no conflict of interest. The funders had no role in the design of the study; in the collection, analyses, or interpretation of data; in the writing of the manuscript, or in the decision to publish the results.

\section{References}

1. $\quad$ Baden, L.R.; El Sahly, H.M.; Essink, B.; Kotloff, K.; Frey, S.; Novak, R.; Diemert, D.; Spector, S.A.; Rouphael, N.; Creech, C.B.; et al. Efficacy and safety of the mRNA-1273 SARS-CoV-2 vaccine. N. Engl. J. Med. 2021, 384, 403-416. [CrossRef] [PubMed]

2. Fowlkes, A.; Gaglani, M.; Groover, K.; Thiese, M.S.; Tyner, H.; Ellingson, K.; Cohorts, H.-R. Effectiveness of COVID-19 vaccines in preventing SARS-CoV-2 infection among frontline workers before and during B.1.617.2 (delta) variant predominance-eight U.S. locations, December 2020-August 2021. MMWR Morb. Mortal. Wkly. Rep. 2021, 70, 1167-1169. [CrossRef] [PubMed] 
3. Cavanaugh, A.M.; Spicer, K.B.; Thoroughman, D.; Glick, C.; Winter, K. Reduced risk of reinfection with SARS-CoV-2 after COVID-19 vaccination-Kentucky, May-June 2021. MMWR Morb. Mortal. Wkly. Rep. 2021, 70, 1081-1083. [CrossRef] [PubMed]

4. Mallapaty, S. COVID vaccines cut the risk of transmitting Delta-but not for long. Nature 2021. [CrossRef] [PubMed]

5. Aschwanden, C. Five reasons why COVID herd immunity is probably impossible. Nature 2021, 591, 520-522. [CrossRef] [PubMed]

6. Centers for Disease Control and Prevention. COVID-19 Vaccinations in the United States. 2021. Available online: https: / / covid.cdc.gov / covid-data-tracker/\#vaccinations_vacc-total-admin-rate-total (accessed on 13 January 2022).

7. Meyer, M.N.; Gjorgjieva, T.; Rosica, D. Trends in health care worker intentions to receive a COVID-19 vaccine and reasons for hesitancy. JAMA Netw. Open 2021, 4, e215344. [CrossRef] [PubMed]

8. Centers for Disease Control and Prevention. Interim Considerations for COVID-19 Vaccination of Healthcare Personnel and Long-Term Care Facility Residents. 2021. Available online: https://www.cdc.gov/vaccines/hcp/acip-recs/vacc-specific/covid19/clinical-considerations.html (accessed on 13 January 2022).

9. Beer, T. COVID-19 Vaccine Mandates are Working-Here's the Proof. 2021. Available online: https:/ /www.forbes.com/sites/ tommybeer/2021/10/04/covid-19-vaccine-mandates-are-working-heres-the-proof/?sh=44cf7ab12305 (accessed on 13 January 2022).

10. Panchal, A.R.; Rivard, M.K.; Cash, R.E.; Corley, J.P., Jr.; Jean-Baptiste, M.; Chrzan, K.; Gugiu, M.R. Methods and implementation of the 2019 EMS practice analysis. Prehosp. Emerg. Care, 2021, epub ahead of print. [CrossRef]

11. Gregory, M.E.; Powell, J.R.; MacEwan, S.R.; Kurth, J.D.; Kenah, E.; Panchal, A.R.; McAlearney, A.S. COVID-19 vaccinations in EMS professionals: Prevalence and predictors. Prehosp. Emerg. Care, 2021, epub ahead of print. [CrossRef]

12. Center for Economic and Social Research. Understanding America Study. 2017. Available online: https://uasdata.usc.edu/index php (accessed on 23 February 2022).

13. Freeman, D.; Loe, B.S.; Chadwick, A.; Vaccari, C.; Waite, F.; Rosebrock, L.; Jenner, L.; Petit, A.; Lewandowsky, S.; Vanderslott, S.; et al. COVID-19 vaccine hesitancy in the UK: The Oxford coronavirus explanations, attitudes, and narratives survey (Oceans) II. Psychol. Med. 2020; Epub ahead of print. [CrossRef]

14. LaVeist, T.A.; Isaac, L.A.; Williams, K.P. Mistrust of health care organizations is associated with underutilization of health services Health Serv. Res. 2009, 44, 2093-2105. [CrossRef] [PubMed]

15. National Registry of Emergency Medical Technicians. National Registry Data, Dashboard, and Maps. Available online: https: / / www.nremt.org/maps (accessed on 13 January 2022).

16. Dillman, D.A.; Smyth, J.D.; Christian, L.M. Internet, Mail, and Mixed-Mode Surveys: The Tailored Design Method, 3rd ed.; Wiley \& Sons: Hoboken, NJ, USA, 2009.

17. Vaismoradi, M.; Turunen, H.; Bondas, T. Content analysis and thematic analysis: Implications for conducting a qualitative descriptive study. Nurs. Health Sci. 2013, 15, 398-405. [CrossRef]

18. Eniola, K.; Sykes, J. Four Reasons for COVID-19 Vaccine Hesitancy among Health Care Workers, and Ways to Counter Them. Available online: https://www.aafp.org/journals/fpm/blogs/inpractice/entry/countering_vaccine_hesitancy.html (accessed on 13 January 2022).

19. Raja, A.S.; Niforatos, J.D.; Anaya, N.; Graterol, J.; Rodriguez, R.M. Vaccine hesitancy and reasons for refusing the COVID-19 vaccination among the U.S. public: A cross-sectional survey. medRxiv 2021. [CrossRef]

20. The World Health Organization. Report of the Sage Working Group on Vaccine Hesitancy. 2014. Available online: https://www. who.int/immunization/sage/meetings/2014/october/1_Report_WORKING_GROUP_vaccine_hesitancy_final.pdf (accessed on 23 February 2022).

21. Kaplan, J. First Responders Willing to Set Example by Getting COVID-19 Vaccine First. 2020. Available online: https:/ /abc11. com/covid-vaccine-nc-distribution-pfizer/8128268/ (accessed on 13 January 2022).

22. Vince, J. DC Firefighters Lead by Example on COVID Vaccine. 2021. Available online: https://www.firehouse.com/safetyhealth/news/21205281/dc-firefighters-lead-by-example-on-covid-vaccine (accessed on 13 January 2022).

23. French, L. Federal Survey Reveals High Public Trust in EMS Services, Providers. Available online: https://www.ems1.com/ research/articles/federal-survey-reveals-high-public-trust-in-ems-services-providers-3Awk1VpaNBBsPKBj/ (accessed on 10 February 2020).

24. National Association of Emergency Medical Technicians. Code of Ethics for EMS Practitioners 2013. Available online: https: / / www.naemt.org/about-ems/code-of-ethics (accessed on 13 January 2022).

25. Centers for Disease Control and Prevention. How to Build Healthcare Personnel's Confidence in COVID-19 Vaccines. 2021 Available online: https://www.cdc.gov/vaccines/covid-19/downloads/Build-Healthcare-Personnel-Confidence.pdf (accessed on 13 January 2022).

26. Cash, R.E.; White-Mills, K.; Crowe, R.P.; Rivard, M.K.; Panchal, A.R. Workplace incivility among nationally certified EMS professionals and associations with workforce-reducing factors and organizational culture. Prehosp. Emerg. Care 2019, 23, 346-355. [CrossRef] [PubMed]

27. Rosenblum, H.G.; Hadler, S.C.; Moulia, D.; Shimabukuro, T.T.; Su, J.R.; Tepper, N.K.; Ess, K.C.; Woo, E.J.; Mba-Jonas, A.; Alimchandani, M.; et al. Use of COVID-19 vaccines after reports of adverse events among adult recipients of Janssen (Johnson \& Johnson) and mRNA COVID-19 vaccines (Pfizer-BioNTech and Moderna): Update from the Advisory Committee on Immunization Practices-United States, July 2021. MMWR Morb. Mortal. Wkly. Rep. 2021, 70, 1094-1099. [CrossRef] [PubMed] 
28. Hamel, L.; Lopes, L.; Sparks, G.; Stokes, M.; Brodies, M. KFF COVID-19 vaccine monitor: April 2021. 2021. Available online: https:/ / www.kff.org/coronavirus-covid-19/poll-finding/kff-covid-19-vaccine-monitor-april-2021/ (accessed on 13 January 2022).

29. Centers for Disease Control and Prevention. Myths and Facts about COVID-19 Vaccines. 2021. Available online: https:/ / www.cdc.gov / coronavirus /2019-ncov/vaccines/facts.html?s_cid=11354:vaccine\%20shedding\%20covid\%20cdc: sem.ga:p:RG:GM:gen:PTN:FY21 (accessed on 13 January 2022).

30. Voci, A. The link between identification and in-group favouritism: Effects of threat to social identity and trust-related emotions. Br. J. Soc. Psychol. 2006, 45, 265-284. [CrossRef] [PubMed]

31. National Academies of Sciences Engineering and Medicine. Communication Strategies for Building Confidence in COVID-19 Vaccines: Addressing Variants and Childhood Vaccinations; The National Academies Press: Washington, DC, USA, 2021.

32. Thayer, A. Trust Trajectories as a Function of Violation Type and Repair Efforts. Ph.D. Thesis, University of Central Florida, Orlando, FL, USA, 2015.

33. Dwyer, C.; Aubrey, A. CDC Now Recommends Americans Consider Wearing Cloth Face Coverings in Public. 2020. Available online: https:/ / www.npr.org/sections/coronavirus-live-updates/2020/04/03/826219824/president-trump-says-cdc-nowrecommends-americans-wear-cloth-masks-in-public (accessed on 13 January 2022).

34. Chamberlain, S. Fauci Emails Show His Flip-Flopping on Wearing Masks to Fight COVID. 2021. Available online: https: // nypost.com/2021/06/03/fauci-emails-show-his-flip-flopping-on-wearing-masks-to-fight-covid/ (accessed on 30 September 2021).

35. Bettendorf, N.; Leopold, J. Anthony Fauci's Emails Reveal the Pressure that Fell on One Man. Available online: https://www. buzzfeednews.com/article/nataliebettendorf/fauci-emails-covid-response (accessed on 13 January 2022).

36. Rouan, R. Fact Check: Missing Context in Claim about Emails, Fauci's Position on Masks. Available online: https://www. usatoday.com/story/news/factcheck/2021/06/03/fact-check-missing-context-claim-mask-emails-fauci/7531267002/ (accessed on 13 January 2021).

37. Brown, S. It Turns Out Dr. Fauci also Knew Masks Weren't Effective against COVID. Available online: https://townhall.com/ tipsheet/spencerbrown/2021/06/02/fauci-emails-n2590347 (accessed on 31 October 2021).

38. Paton, J. WHO Envoy Warns of Increasing Risk of COVID Variants Evading Vaccines. Available online: https://www.bloomberg. $\mathrm{com} /$ news/articles/2021-09-13/who-envoy-warns-of-increasing-risk-of-variants-evading-vaccines (accessed on 13 January 2022).

39. Goodman, B. Chance that COVID-19 Vaccines Are Gene Therapy? 'Zero'. Available online: https://www.webmd.com/lung/ news / 20210719/covid-19-vaccines-not-gene-therapy (accessed on 13 January 2022).

40. National Highway Traffic Safety Administration. The National EMS Education Standards. 2009. Available online: https: //www.ems.gov/pdf/National-EMS-Education-Standards-FINAL-Jan-2009.pdf (accessed on 13 January 2022).

41. Riad, A.; Abdulqader, H.; Morgado, M.; Domnori, S.; Koscik, M.; Mendes, J.J.; Klugar, M.; Kateeb, E.; Iads-Score, O.B.O. Global prevalence and drivers of dental students' COVID-19 vaccine hesitancy. Vaccines 2021, 9, 566. [CrossRef] [PubMed]

42. Klugar, M.; Riad, A.; Mohanan, L.; Pokorna, A. COVID-19 vaccine booster hesitancy (VBH) of healthcare workers in Czechia: National cross-sectional study. Vaccines 2021, 9, 1437. [CrossRef] [PubMed]

43. Sallam, M. COVID-19 vaccine hesitancy worldwide: A concise systematic review of vaccine acceptance rates. Vaccines 2021, 9 , 160. [CrossRef] [PubMed]

44. Our World in Data. Coronavirus (COVID-19) Vaccinations. 2022. Available online: https://ourworldindata.org/covidvaccinations (accessed on 23 February 2022).

45. Shah, A.; Seerval, S.; Schneider, E.C. How Can the U.S. Catch Up with Other Countries on COVID-19 Vaccination? 2021. Available online: https:/ / www.commonwealthfund.org/blog/2021/how-can-us-catch-other-countries-covid-19-vaccination (accessed on 23 February 2022).

46. Schmuhl, P.; Van Duker, H.; Gurley, K.L.; Webster, A.; Olson, L.M. Reaching emergency medical services providers: Is one survey mode better than another? Prehosp. Emerg. Care 2010, 14, 361-369. [CrossRef] [PubMed]

47. Cash, R.E.; Rivard, M.K.; Camargo, C.A.; Powell, J.R.; Panchal, A.R. Emergency medical services personnel awareness and training about personal protective equipment during the COVID-19 pandemic. Prehosp. Emerg. Care 2021, 25, 777-784. [CrossRef] [PubMed]

48. Cash, R.E.; Crowe, R.P.; Rodriguez, S.A.; Panchal, A.R. Disparities in feedback provision to emergency medical services professionals. Prehosp. Emerg. Care 2017, 21, 773-781. [CrossRef] [PubMed]

49. Crowe, R.P.; Fernandez, A.R.; Pepe, P.E.; Cash, R.E.; Rivard, M.K.; Wronski, R.; Anderson, S.E.; Hogan, T.H.; Andridge, R.R.; Panchal, A.R.; et al. The association of job demands and resources with burnout among emergency medical services professionals. J. Am. Coll. Emerg. Physicians Open 2020, 1, 6-16. [CrossRef] [PubMed]

50. Andel, S.A.; Pindek, S.; Spector, P.E. Being called to safety: Occupational callings and safety climate in the emergency medical services. J. Occup. Environ. Med. 2016, 58, 1245-1249. [CrossRef] [PubMed] 